\title{
A Promotion of VRV System Control in Office Building
}

\author{
Qingping $\mathrm{Li}^{1, \mathrm{a}}$,Hongwei Wang ${ }^{2, \mathrm{~b}}$, Guojian Wang ${ }^{1, \mathrm{a}}$, Song Pan ${ }^{2, \mathrm{c}, *}$, Xiaojun \\ Zhang ${ }^{3, a}$,Congcong $\mathrm{Xu}^{3, \mathrm{a}}$,Shaolin Zhang ${ }^{4, a}$ \\ ${ }^{1}$ Beijing Institute of Residential Building Design\&Research CO.,LTD,China \\ ${ }^{2}$ Building Environment and Energy Applications Engineering, \\ Beijing University of Technology,China \\ ${ }^{3}$ Ministry of Housing and Urban-Rural Development,China \\ ${ }^{4}$ Lushang Property CO.,LTD,China \\ awgj86365413@126.com, b422508289@qq.com, c15010100895@163.com \\ Corresponding Author:Song Pan ${ }^{2, \mathrm{C}}$
}

\begin{abstract}
Keywords: Office building, Intelligent algorithm, Variable refrigerant volume (VRV), Ceiling fan Abstract. VRV system is a more effective and energy-saving central air-conditioning system in office buildings due to its variable load modes and flexibility in adjusting refrigerant, compared with all-air air-conditioning system and air-water air-conditioning system. Nevertheless, VRV system is less applied to office buildings than the other systems because the system is lack of fresh air supplying, united control system and data collection. This paper summarizes the advantages of VRV system in office buildings and presents current VRV system and central air-conditioning control methods. In the end, the paper puts forward three ways to improve VRV system application in office buildings by adding ceiling fan system, transplanting intelligent algorithm and adopting practical office building for testing and performance assessment.
\end{abstract}

\section{Introduction}

Office building is a typical kind of public building, of which the air-conditioning system consumed considerable energy, almost about 40\%-55\%[1] of the building energy consumption. Central air-conditioning system, mainly assembled with the unit of fan cooling and air handling, is commonly adopted in this kind of building. It has become a huge challenge for the conventional central air-conditioning system that how to fulfill both the requirement of independent control of each fan cooling unit to accommodate the variation of room load and strengthen the robustness of system, and the demand for indoor air quality.

Variable refrigerant volume air-conditioning system is a newly developing air-conditioning system in the past three decades. VRV air-conditioning system takes the advantage of changing the refrigerant volume that runs through the compressor and the heat exchanger to realize heating/cooling. This kind of system is much better than the traditional air-conditioning system due to its specific control of refrigerant volume on the basis of practical room load to fit in the comprehensive range of variation and its flexibility of handled-air distribution. Compared with all-air air-conditioning system and air-water air-conditioning system, VRV air-conditioning system is more adaptive for the office building with variable room load and has higher operation performance which contributes to high efficiency and energy-saving. The advantages of VRV air-conditioning system used in the office building is as follows:

(1)VRV system has a high efficiency, which is one of the most prominent features. The method of maximum room load to choose the volume of facility is widely applied in the design of central air-conditioning system. Regardless of the tiny occasion when maximum room load occurs in real life, this method calls for on-off control to adjust temperature which causes a waste of energy and a poor efficiency of air-conditioning units. On the other hand, dealing with the same variable room load condition, VRV has a developing capability of heat exchanging and cooling efficiency. 
(2) VRV system has an excellent adjusting performance. Central air conditioning system generally changes the air current indoor or the supply air temperature when room load or setting temperature alters. The means of energy adjusting of the entire system relies on the on-off control of compressor. Because of hysteresis effect of the system, this kind of adjusting method has longer feedback time and lower accuracy. On the other side, VRV system is composed of advanced compressor variable refrigerant volume technology and electronic expansion valve (EEV) control technique.

(3)The component removal of VRV system, such as cooling tower, chilled water pump, cooling water pump, water pipe, air duct, blast gate, water valve, expansion tank and water treatment equipment etc., not only simplifies the system and assures the reliability of the system, but reduces the demand for the height and space of the building.

(4)On account of the vast range of load adjusting and the flexibility of air distribution, VRV system is capable of varying load of each room automatically when the peak of room load turns up in different directions of building.

Above all, VRV system is more suitable for office buildings apart from the drawback of incapacity of fresh air supplying. However, most current control strategies of air-conditioning system like neural network control and fuzzy control aim to control the all-air air-conditioning system and air-water air-conditioning system because VRV system is highly coupled with fresh air system, which means an increase in parameters and complication of the whole control system, leading to a hardship of constructing intelligent algorithm. Hence, there is a lack of control strategy of VRV and fresh air system(VRV-Fresh system), which is vitally important and promising in the future.

\section{Research of control strategy of VRV system and central air-conditioning system}

VRV system is being further studied for its energy saving potential. Zhou[2] reported the result that VRV system declined energy consumption contrasted with fan coil unit based on the simulation in EnergyPlus. Aynur[3] compared VRV system with VAV(variable air volume) system in an office building and concluded that VRV system can decrease $27.1 \%-57.9 \%$ of energy consumption. Park[4] studied the relationship of rotate speed of compressor, cooling load, air distribution of two rooms and the system performance in a system contained one outdoor air conditioner and two indoor air conditioners, and made a conclusion that the energy consumption has a direct proportion with rotate speed squared and a inverse proportion with COP of the system.

The development of VRV system control strategy was divided into two parts: centralized control and decentralized control. Centralized control was primarily applied in previous control system. It was a net communication method that comprised central controller, data bus, and terminal device to realize the data transmission between central controller with outdoor and indoor air conditioner. It was presented in the paper of Masuda[5] that there was a correlation of compressor rotate speed, swell valve and room load through experimental curve, and thus a controller of outdoor air conditioner was established. While it was beneficial for understanding entire system when using centralized control, the model of VRV system still needed to be revised for the variation of indoor air conditioners and heat volume due to the enormous transmission of information. Decentralized control was born for predigesting the transmission of information via proposing a way of controlling outdoor air conditioner and indoor air conditioner separately.

Central air-conditioning system belongs to a typical system with distributed parameters, obvious hysteresis, coupled loop and non-linearity. Constructing mathematical model of controlled object and controller is precondition of design, simulation and performance evaluation. It is inapplicable for the description of non-linear system on the basis of the classical control theory and the modern dynamic modeling theory. Therefore, modeling and control theory basing on intelligent algorithm is being taken into account remarkably.

The most two representative methods of intelligent control applied in HVAC system is fuzzy model control and neural networks control. Fuzzy control mainly has two models: Manmdani model (M model) and Takagi-Sugeno model (T-S model). It was previously established in Tobi's paper[6] that $\mathrm{M}$ model fuzzy control was combined with two inputs (room temperature and humidity), three 
outputs (hot water valve, chilled water valve and humidifier valve). Pedrycz[7] put forward M model fuzzy control designed for air conditioner. Zhang presented fuzzy rule compatibility of optimizing fuzzy model[8], optimization based on characteristics of phase plane trajectory[9] and optimization based on self-adjusting[10].

Neural network is being widely adapted in air-conditioning system modeling and control due to its self-study, variable inputs and outputs and nonlinear approximation. Zhang[11] provided multistep prediction fuzzy control on the basis of Elman network and BP network, adding first and second derivative into the inputs. Wai[12] developed an online data collecting system, providing cooling coil neural network data.

At present, neural network has become a effective method building a dynamic air-conditioning system and is being applied in actual system.Since VRV system and intelligent algorithm on central air-conditioning system have been carried out for a long time, there are few researches studying applying neural network into VRV system, which will be a promising aspect of promoting control method of VRV system.

\section{Conclusion}

As what has been illustrated in this paper, VRV system will be a popularity of future central air-conditioning system for its convenience, stability and flexibility. Nevertheless, there still remains a vital problem for its extensive application on account of control method of the system included VRV system and fresh air system. Hence, there is a need to study how to transplant intelligent control from conventional central air-conditioning system to VRV-Fresh system and building the control method in practical construction to test its feasibility. The future work that can contribute to the system application is shown as follows:

(1)Improve the system. Though VRV-Fresh system is more energy-saving than conventional air-conditioning system, there still remains a potential in saving energy by taking the ceiling fan into account. As a primitive means of air-conditioning, ceiling fan has been abandoned for its incapability of hypothermia and uncomfortable blowing feeling, which probably results in healthy problem. However, appropriate location of ceiling fan can decrease the uncomfortable blowing feeling and adjust airflow instead of the function of air-conditioning system, which takes another chance in saving energy. The VRV-Fresh-Fan coupled system may reduce energy consumption rapidly once the control system is well designed and runs effectively.

(2)Transplant the intelligent algorithm. BP neural network is adept in managing non-linear problem and has a precise prediction of variation, which is definitely fit with highly coupled system such as VRV-Fresh-Fan system. Combined with fuzzy control, this control system is able to collect and transfer data immediately so that the system can do fast response with high accuracy. Also, all the data can be shared online, achieving the goal of visualization and checking easily. The future work is divided into two parts. One is establishing BP neural network, including setting sensors, collecting data, figuring out input parameters and training algorithm. The other is simulating BP neural network with fuzzy control model to test whether the allied system runs successfully and effectively.

(3)Practical test. After construction and simulation of the system, a practical test is needed to confirm the system can be accomplished in reality. Basing on the office building VRV-Fresh-Fan system, provided by Beijing Institute Of Residential Building Design\&Research(BRDR), the intelligent control system will be applied and evaluated for its operation, performance and energy-saving.In addition, the control system will be joint with building information modeling (BIM), developed by BRDR, to realize visualization and online monitoring. The test result is useful for promoting the control system and beneficial for spreading and manufacturing the system, which will further play an important role in energy-saving. 


\section{Acknowledgements}

This work was financially supported by special fund of Beijing Key Laboratory of Green Building and Energy-efficiency Technology, the National Natural Science Foundation of China (51578001), 2015 Science and technology project plan of Ministry of Housing and Urban-Rural Development of the People’s Republic of China(2015-R1-013).

\section{References}

[1] Lu Li: Research on energy consumption model and management information system of large public buildings (In Chinese,2014).

[2] Yanping Zhou and JingYi Wu: Energy and Buildings, 39, p.212 (2007).

[3] T.N. Aynur, Y.H. Wang and R. Radermacher: Energy and Buildings, 41(11), p.1143 (2009).

[4] Y.C. Park, Y.C. Kim and M.K. Min: Energy Conversion and Management, 42(13), p.1607 (2001).

[5] M. Masuda and K. Wakahara:Development of a multi-system air conditioner for residential use (ASHRAE Trans, America 1991).

[6] T. Tobi and T. Hanafusa: International Journal of Approximate Reasoning, 5(3), p.331 (1991).

[7] W. Pedrycz, in:Fuzzy Control and Fuzzy Systems (2nd Edition), New York, Research Studies Press (1993).

[8] Jili Zhang and Jingping Ou, in:Fuzzy control rule optimization method based on fuzzy set compatibility, Fuzzy systems and Mathematics, 16(4), p.81 (In Chinese,2002).

[9] Jili Zhang and Jingping Ou, in:Self adjustment fuzzy control method based on phase plane trajectory feature, Control theory and Application, 20(4), p.607 (In Chinese,2003)

[10] Hui Li and Jili Zhang, in:Method of self organizing fuzzy control for the rule of double phase extraction, Journal of Harbin Institute of Technology, 37(9), p.1189 (In Chinese,2005)

[11] Jili Zhang:Fuzzy neural network control theory and its application in building thermal process (In Chinese,1999)

[12] L.T. Wai and L.C. Wai: Measurement, 37(1), p.39 (2005). 